\title{
SEARCH FOR NEW DRUGS
}

\section{SYNTHESIS AND ANTIPLATELET AND ANTICOAGULANT ACTIVITY OF THIETANE-CONTAINING 2-(5-BROMO- 2,4-DIHYDRO-3-OXO-1,2,4-TRIAZOLYL-4)ACETATE SALTS}

\author{
K. G. Gurevich, ${ }^{1}$ A. L. Urakov, ${ }^{2,}{ }^{*}$ G. A. Rozit, ${ }^{3}$ E. É. Klen, ${ }^{3}$ \\ A. V. Samorodov, ${ }^{3}$ and F. A. Khaliullin ${ }^{3}$
}

Translated from Khimiko-Farmatsevticheskii Zhurnal, Vol. 55, No. 5, pp. 3 - 8, May, 2021.

Original article submitted March 25, 2021.

Sulfone II was synthesized via oxidation of ethyl 2-[5-bromo-2,4-dihydro-3-oxo-2-(thietanyl-3)-1,2,4-triazolyl-4]acetate (I) by $\mathrm{H}_{2} \mathrm{O}_{2}$. Hydrolysis of esters I and II synthesized 2-[5-bromo-2,4-dihydro3-oxo-2-(thietanyl-3)-1,2,4-triazolyl-4]- and 2-[5-bromo-2,4-dihydro-3-oxo-2-(1,1-dioxothietanyl-3)-1,2,4triazolyl-4]acetic acids III and IV, respectively. Water-soluble salts $\mathbf{V}$ and $\mathbf{V I}$ were prepared by reacting acids III and IV with alkali-metal hydroxides and amines. The structures of the synthesized compounds were confirmed IR and NMR spectroscopic data. The antiplatelet and anticoagulant activity of the synthesized compounds was studied in vitro based on predictions of the PASS computer program. Compounds III and VIb, which showed the absence of predicted toxic risks and were superior to the reference drug in the collagen-induced aggregation test, had the most pronounced antiplatelet activity (comparable to that of acetylsalicylic acid) in the ADP-induced aggregation test. The anticoagulant activity of the compounds was significantly inferior to that of heparin sodium. All synthesized compounds satisfied Lipinski's rule-of-5.

Keywords: 2,4-dihydro-1,2,4-triazol-3-one, thietane, antiplatelet activity, anticoagulant activity, Lipinski's rule-of-5.

Thrombohemorrhagic disorders are currently the most common types of human pathologies [1]. Thrombi and associated complications are some of the causes of invalidism and lethality among the total causes of death of the geriatric population [2]. Therapy of clots has become especially critical because of emergent coronavirus infections $[3,4]$. Antiplatelet drugs such as ticlodipine, clopidogrel, flurbiprofen, ozagrel, lotrafiban, and acetylsalicylic acid are currently used to treat and prevent thrombi. However, several side effects can be associated with their use [5-7]. Therefore, the development of new domestic drugs capable of cor-

1 A. I. Evdokimov Moscow State University of Medicine and Dentistry, Ministry of Health of the Russian Federation, 20/1 Delegatskaya St., Moscow, 127473 Russia.

2 Izhevsk State Medical Academy, Ministry of Health of the Russian Federation, 281 Kommunarov St., Izhevsk, 426034 Russia.

${ }^{3}$ Bashkir State Medical University, Ministry of Health of the Russian Federation, 3 Lenina St., Ufa, Bashkortostan, 450008 Russia.

e-mail: urakoval@live.ru recting the hemostasis system is crucial. Previous research on the synthesis of 1-thietanyl-1,2,4-triazole derivatives demonstrated that they were promising for preparing new biologically active compounds with antiplatelet activity $[8,9]$. Therefore, the aim of the present work was to synthesize new thietane-containing 2-(5-bromo-2,4-dihydro-3-oxo-1,2,4-triazolyl-4)acetic acid derivatives and to assess preliminarily their antiplatelet and anticoagulant activity.

\section{EXPERIMENTAL CHEMICAL PART}

The target compounds were synthesized according to Scheme 1.

PMR spectra were recorded in $\mathrm{CDCl}_{3}$ and DMSO- $\mathrm{d}_{6}$ on a Bruker AM-300 instrument at operating frequency $300 \mathrm{MHz}$ for ${ }^{1} \mathrm{H}$. The internal standards were solvent resonances at $2.50 \mathrm{ppm}\left(\mathrm{DMSO}_{-} \mathrm{d}_{6}\right)$ and $7.26 \mathrm{ppm}\left[\mathrm{CD}(\mathrm{H}) \mathrm{Cl}_{3}\right]$. IR spectra were taken from $\mathrm{KBr}$ pellets on an Infralum FT-02 


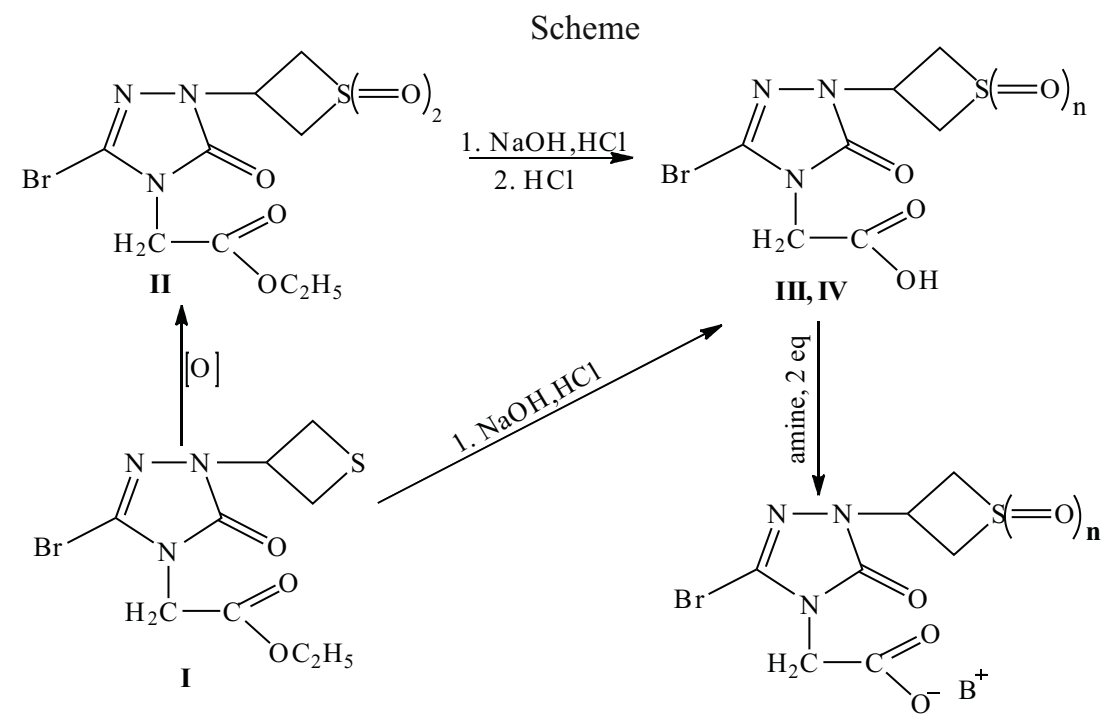

$n=0$ (Va-e); 2 (Via-e)

$\mathrm{B}=\mathrm{K}+($ Va, VIa $), \mathrm{Na}^{+}(\mathbf{V b}, \mathbf{V I b}), \mathrm{H}_{3} \mathrm{~N}^{+} \mathrm{C}\left(\mathrm{CH}_{2} \mathrm{OH}\right)_{3}(\mathbf{V c}, \mathbf{V i c})$,

$\mathrm{H}_{3} \mathrm{~N}^{+} \mathrm{CH}_{2} \mathrm{CH}_{2} \mathrm{OH}(\mathbf{V d}), \mathrm{N}_{2} \mathrm{~N}^{+}\left(\mathrm{C}_{2} \mathrm{H}_{4} \mathrm{OH}\right)_{2}(\mathbf{V e})$,

$\mathrm{H}_{3} \mathrm{~N}^{+} \mathrm{CH}_{2} \mathrm{C}_{6} \mathrm{H}_{5}$ (VId), $\mathrm{H}_{3} \mathrm{~N}^{+} \mathrm{C}_{6} \mathrm{H}_{11}$ (VIe)

instrument. Melting points were measured on an SMP30 apparatus. The purity of compounds was confirmed by TLC on Sorbfil PTSKh-P-A-UF plates using $\mathrm{CHCl}_{3}-\mathrm{EtOH}(9: 1, \mathrm{v} / \mathrm{v})$ and hexane-EtOH (5:5). Spots were detected by $\mathrm{I}_{2}$ vapor in a humid chamber. Elemental analyses were performed on a Hekatech Euro3000 CHNS analyzer. Analyses for C, H, N, and $\mathrm{S}$ agreed with the calculated values. Table 1 presents the characteristics of the synthesized compounds and spectral data.

Ethyl 2-[5-bromo-2,4-dihydro-2-(1, 1-dioxothietanyl3)-3-oxo-1,2,4-triazolyl-4]acetate (II). Compound 1 $(4.42 \mathrm{~g}, 14 \mathrm{mmol})$ in glacial HOAc $(135 \mathrm{~mL})$ was treated with $\mathrm{H}_{2} \mathrm{O}_{2}(37 \%, 12.86 \mathrm{~g}, 140 \mathrm{mmol})$. The mixture was refluxed for $1 \mathrm{~h}$, cooled to room temperature, and neutralized to $\mathrm{pH} 7.0$ with $\mathrm{NH}_{4} \mathrm{OH}$ solution. The resulting precipitate was filtered off, rinsed with $\mathrm{H}_{2} \mathrm{O}$, and dried.

2-[5-Bromo-2,4-dihydro-3-oxo-2-(thietanyl-3)-1,2,4triazolyl-4]acetic acid (III). Ester I (10.74 g, $33 \mathrm{mmol})$ was added to a solution of $\mathrm{NaOH}(2.64 \mathrm{~g}, 66 \mathrm{mmol})$ in $\mathrm{H}_{2} \mathrm{O}$ $(265 \mathrm{~mL})$. The mixture was stirred at room temperature for 1 d. The unreacted precipitate was filtered off. The filtrate was treated with $\mathrm{HCl}$ to $\mathrm{pH} 3.0-4.0$. The resulting precipitate was filtered off, rinsed with $\mathrm{H}_{2} \mathrm{O}$, and dried.

2-[5-Bromo-2,4-dihydro-2-(1, 1,-dioxothietanyl-3)-3oxo-1,2,4-triazolyl-4]acetic acid (IV). A. Ester II ( $0.50 \mathrm{~g}$, $14 \mathrm{mmol})$ was added to a solution of $\mathrm{NaOH}(0.22 \mathrm{~g}$, $56 \mathrm{mmol})$ in $\mathrm{H}_{2} \mathrm{O}(20 \mathrm{~mL})$. The mixture was stirred at room temperature for $2 \mathrm{~d}$. The unreacted precipitate was filtered off. The filtrate was treated with $\mathrm{HCl}$ to $\mathrm{pH} 3.0-4.0$. The resulting precipitate was filtered off, rinsed with $\mathrm{H}_{2} \mathrm{O}$, and dried. B. Ester II $(2.72 \mathrm{~g}, 7 \mathrm{mmol})$ was treated with $\mathrm{H}_{2} \mathrm{O}$ $(20 \mathrm{~mL})$ and conc. $\mathrm{HCl}(10 \mathrm{~mL})$. The mixture was refluxed for $2 \mathrm{~h}$ and cooled. The resulting precipitate was filtered off, rinsed with $\mathrm{H}_{2} \mathrm{O}$, and dried.

General method for synthesizing salts Va, b and VIa, b. A solution of $\mathrm{KOH}$ or $\mathrm{NaOH}(3.3 \mathrm{mmol})$ in $i-\mathrm{PrOH}$ $(35 \mathrm{~mL})$ and $\mathrm{H}_{2} \mathrm{O}(1 \mathrm{~mL})$ was treated with acid III or IV $(3 \mathrm{mmol})$. The mixture was refluxed for $10 \mathrm{~min}$ and cooled. The resulting precipitate was filtered off, rinsed with $i$-PrOH, dried, and purified by crystallization from $i-\mathrm{PrOH}$.

General method for synthesizing salts Vc-e and VIc-e. Acid III or IV (3 mmol) was treated with $i-\mathrm{PrOH}(15 \mathrm{~mL})$, heated until dissolved, and treated with an amine $(6 \mathrm{mmol})$. The mixture was refluxed for $10 \mathrm{~min}$ and cooled. The resulting precipitate was filtered off, rinsed with $i-\mathrm{PrOH}$, dried, and purified by crystallization from $i$-PrOH.

Toxicity and drug-likeness of the synthesized compounds were predicted by the Osiris DataWarrior program [10]. The biological activity of the synthesized compounds was predicted from the chemical structural formula using the online version of the PASS computer program [11].

\section{EXPERIMENTAL BIOLOGICAL PART}

Experiments were conducted according to Good Laboratory Practice Rules of the Eurasian Economic Union on Circulation of Medicines [12].

Antiplatelet and anticoagulant activity were assessed in vitro using isolated blood samples from 25 healthy male donors aged $18-24$ years. The study was approved by the Ethics Committee of Bashkir State Medical University, Ministry of Health of Russia (No. 2 of Oct. 17, 2012). Informed consent was obtained from all study participants before blood collection. 
TABLE 1. Characteristics of Synthesized II-VI

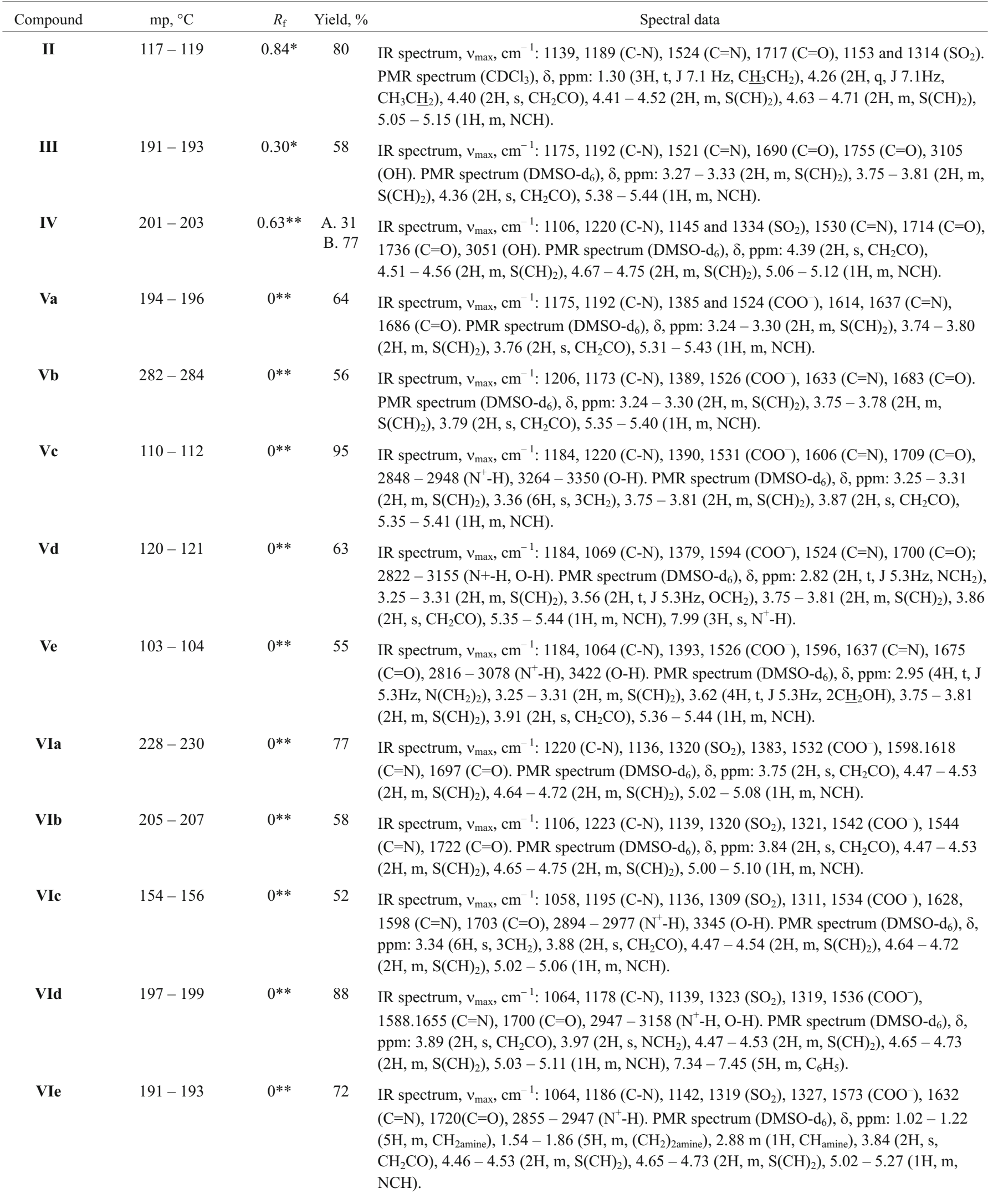

\footnotetext{
${ }^{*}$ Chromatography using hexane-EtOH (5:5);

** Chromatography using $\mathrm{CHCl}_{3}-\mathrm{EtOH}(9: 1)$.
} 
The effect of the compounds on platelet aggregation was studied using the Born method [13] on an AT-02 aggregometer (Medtekh NPF, Russia). Antiplatelet activity of the tested compounds and reference drugs was assessed at a final concentration of $1 \times 10^{-3} \mathrm{M}$. The aggregation inductors were adenosine diphosphate (ADP) at a concentration of $20 \mu \mathrm{g} / \mathrm{mL}$ and collagen at a concentration of $5 \mathrm{mg} / \mathrm{mL}$ (Tekhnologiya-Standart, Russia). The reference drugs were pentoxifylline (Pentoxifylline, $20 \mathrm{mg} / \mathrm{mL}$ solution for injection, 5-mL ampuls; JSC Dalkhimfarm, Russia) and acetylsalicylic acid (substance-powder; Shandong Xinhua Pharmaceutical Co. Ltd., China).

Anticoagulant activity was determined in clotting tests [14] on a Solar CGL 2110 turbidimetric hemocoagulometer (CSC SOLAR, Belarus). The final concentration of the tested compounds and reference drug was $5 \times 10^{-4} \mathrm{~g} / \mathrm{mL}$. The activated partial thromboplastin time (APTT), prothrombin time (PT), and fibrinogen concentration were studied according to A. Clauss. The reference drug was heparin sodium (heparin sodium, $5000 \mathrm{IU} / \mathrm{mL}$, solution for injection, 1-mL ampuls; JSC Sintez, Russia).

Statistical analysis used the Statistica 10.0 software (StatSoft Inc., USA). A check for normal distributions of actual data used the Shapiro-Wilk criterion. The distribution of the obtained results was found to differ from normal. Therefore, nonparametric methods were used for further work. The obtained results were given as medians and 25 and 75 percentiles. Dispersion analysis used the Kruskal-Wallis criterion. The critical significance level $p$ for statistical criteria was taken as 0.05 [15].

\section{RESULTS AND DISCUSSION}

Starting ethyl 2-[5-bromo-2,4-dihydro-3-oxo-2-(thietanyl-3)-1,2,4-triazolyl-4]acetate (I) was synthesized by the literature method [16]. Oxidation of $\mathbf{I}$ by a 10 -fold molar excess of $\mathrm{H}_{2} \mathrm{O}_{2}$ in glacial HOAc with heating produced ethyl 2[(5-bromo-2,4-dihydro-3-oxo-2-(1,1-dioxothietanyl-3)-1,2,4triazolyl-4]acetate (II) in $80 \%$ yield (Scheme 1). The PMR spectrum of sulfone II showed weak-field shifts of 1.2 and $0.7 \mathrm{ppm}$ for the multiplets of the two $\mathrm{S}(\mathrm{CH})_{2}$ groups of the thietane dioxide ring and a strong-field shift by $0.4 \mathrm{ppm}$ for the multiplet of the $\mathrm{NCH}$ proton relative to the analogous resonances of the unoxidized thietane ring.

Acid III was prepared in $58 \%$ yield (Scheme 1) via alkaline hydrolysis of ester I by a two-fold molar excess of aqueous $\mathrm{NaOH}$ at room temperature. Hydrolysis of ester II under analogous conditions led to the formation of acid IV in 31\% yield (Scheme 1). The yield of IV was increased to $77 \%$ by acid hydrolysis of II using $\mathrm{HCl}$ solution and heating. The formation of acids III and IV was confirmed by the appearance in their IR spectra of absorption bands for O-H stretching vibrations at $3051-3105 \mathrm{~cm}^{-1}$ (Table 1). PMR spectra of acids III and IV lacked resonances for ethoxy protons.

Salts of K (Va and VIa) and Na (Vb and VIb) were synthesized in $58-77 \%$ yields (Scheme 1) by reacting acids III and IV with a slight excess of $\mathrm{KOH}$ or $\mathrm{NaOH}$ in $i-\mathrm{PrOH}$. Alkylammonium salts Vc-e and VIc-e were synthesized in $83-95 \%$ yields (Scheme 1 ) by heating acids III and IV with a two-fold molar excess of the amines in $i$-PrOH. Formation of salts Va-e and VIa-e was confirmed by the presence in their IR spectra (Table 1) of absorption bands for stretching vibrations of carboxylate ions at $1319-1390$ and

TABLE 2. Biological Activity of II-VI Predicted by the PASS Online Computer Program

\begin{tabular}{|c|c|c|c|c|c|}
\hline \multirow[b]{2}{*}{ Compound } & \multicolumn{5}{|c|}{ Probability of biological activity (Pi) } \\
\hline & hematopoiesis inhibition & $\begin{array}{c}\text { platelet adhesion inhibi- } \\
\text { tion }\end{array}$ & $\begin{array}{l}\text { platelet activity suppres- } \\
\text { sion }\end{array}$ & $\begin{array}{c}\text { fibrinogen receptor block- } \\
\text { age }\end{array}$ & $\begin{array}{c}\text { P2T-purinergic receptor } \\
\text { blockage }\end{array}$ \\
\hline III & 0.308 & 0.379 & 0.118 & 0.448 & 0.068 \\
\hline IV & 0.279 & 0.412 & 0.181 & 0.553 & 0 \\
\hline $\mathrm{Ve}$ & 0.380 & 0.408 & 0.151 & 0.460 & 0.160 \\
\hline Vd & 0.388 & 0.411 & 0.148 & 0.458 & 0.120 \\
\hline Ve & 0.385 & 0.400 & 0.140 & 0.452 & 0.134 \\
\hline VIa & 0.219 & 0.328 & 0 & 0.371 & 0 \\
\hline VIe & 0.230 & 0.332 & 0 & 0.360 & 0 \\
\hline
\end{tabular}


TABLE 3. Effect of II-VI and Reference Drugs on Platelet Aggregation and Plasma Hemostasis, Me (0.25 - 0.75)

\begin{tabular}{|c|c|c|c|}
\hline Compound & $\begin{array}{l}\text { ADP-induced change of platelet } \\
\text { aggregation, \% vs. control }\end{array}$ & $\begin{array}{l}\text { Collagen-induced change of platelet } \\
\text { aggregation, } \% \text { vs. control }\end{array}$ & $\begin{array}{c}\text { APTT increase, } \% \text { vs. } \\
\text { control }\end{array}$ \\
\hline II & $-6.4(4.9-8.3)^{*, \dagger \dagger, \#}$ & $-4.5(3.8-6.5)^{*, \dagger \dagger}$ & $6.4(4.9-7.6)^{*}$ \\
\hline IV & $-11.4(10.1-13.7)^{*}, \dagger$ & $-10.4(9.1-12.3)^{*, \dagger \dagger, \# \# ~}$ & $3.1(2.5-4.1)$ \\
\hline Va & $-11.5(9.4-12.2)^{*,+\dagger}$ & $-10.3(8.7-11.2)^{*, \dagger \dagger, \# \# ~}$ & $5.3(4.8-6.7)^{*}$ \\
\hline Vd & $-6.5(5.8-7.7)^{*, \dagger \dagger, \#}$ & 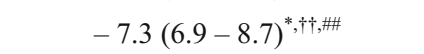 & $8.3(7.1-9.4)^{*}$ \\
\hline Ve & $-7.8(6.3-8.9)^{*}, \grave{i}, \#$ & $-8.1(6.9-9.1)^{*, \dagger \dagger, \# \# ~}$ & $8.5(6.2-9.7)^{*}$ \\
\hline VIa & $-9.4(8.5-11.7)^{*, \dagger \dagger}$ & $-2.3(1.4-3.7)^{\dagger \dagger, \# \#}$ & $5.6(4.9-6.7)^{*}$ \\
\hline VIb & $-15.3(14.8-17.1)^{* *, \dagger \dagger}$ & $-16.3(15.1-17.4)^{* *, \dagger \dagger, \# \#}$ & $9.2(8.3-11.1)^{*}$ \\
\hline Acetylsalicylic acid & $-13.7(10.8-16.4)^{*, \dagger \dagger}$ & $0.0(0.0-0.0)$ & - \\
\hline Pentoxifylline & $-48.4(42.7-56.5)^{* *, \# \#}$ & $0.0(0.0-0.0)$ & - \\
\hline Heparin sodium & - & - & $54.7(47.7-60.2)^{* *}$ \\
\hline
\end{tabular}

${ }^{*} p \leq 0.05 ;{ }^{* *} p \leq 0.001$ vs. the control; ${ }^{\dagger} p \leq 0.05,{ }^{\dagger \dagger} p \leq 0.001$ vs. pentoxifylline; ${ }^{\#} p \leq 0.05,{ }^{\# \#} p \leq 0.001$ vs. acetylsalicylic acid; vs. heparin so$\operatorname{dium} p<0.05 ; n=6$.

$1526-1594 \mathrm{~cm}^{-1}$. IR spectra of alkylammonium salts Vc-e and VIc-e showed absorption bands for stretching vibrations of $\mathrm{N}^{+}-\mathrm{H}$ groups in the range $2816-3078 \mathrm{~cm}^{-1}$. Resonances for protons of the corresponding amines in PMR spectra of Va-e confirmed that salts Ve-e and VIc-e formed. For example, spectra of Ve and VIc showed a $6 \mathrm{H}$ singlet at $\sim 3.3 \mathrm{ppm}$ that belonged to the protons of the $3 \mathrm{CH}_{2}$ groups of Tris-amine.

The biological activity of the synthesized compounds predicted by the PASS program (Table 2) showed that II-VI with probability $\mathrm{Pi}=0.2-0.4$ could inhibit adhesion of platelets and hematopoiesis and act as platelet antagonists $(\mathrm{Pi}$ $\sim 0.1$ ), fibrinogen receptors ( $\mathrm{Pi} \sim 0.4-0.6$ ), and purine P2T-receptors $(\mathrm{Pi} \sim 0.1)$. Therefore, antiplatelet and anticoagulant activity of the synthesized compounds was studied in in vitro experiments.

Acid III $(-14.3 \%, p \leq 0.05)$ and its K salt Va $(-11.5 \%$, $p \leq 0.05)$ among thietanyl derivatives III and $\mathbf{V}$ showed statistically significant antiplatelet effects that were comparable to that of acetylsalicylic acid in the ADP-induced platelet aggregation test. The effect decreased slightly to $-11.4 \%$ for acid IV and to $-9.4 \%$ for $\mathrm{K}$ salt VIa if the oxidation state of the $\mathrm{S}$ atom was increased to the sulfone. The $\mathrm{Na}$ salt $\mathbf{V I b}$ $(-15.3 \%, p \leq 0.05)$ showed an antiplatelet effect comparable to that of acetylsalicylic acid. However, the antiplatelet effect of III, Va, and VIb was significantly (by $3.2-4.2$ times) inferior to that of pentoxifylline (Table 3 ).
TABLE 4. Predicted Toxicity, Drug-Likeness, and Lipinski's Rule-of-5 Agreement of Synthesized Compounds in Osiris DataWarrior Program

\begin{tabular}{cccccccc}
\hline $\begin{array}{c}\text { Com- } \\
\text { pound }\end{array}$ & $\begin{array}{c}\text { Toxic } \\
\text { risk }^{*}\end{array}$ & $\log P$ & $\begin{array}{c}\text { Mol } \\
\text { weight }\end{array}$ & $\begin{array}{c}\text { TPSA, } \\
\AA^{2}\end{array}$ & nOH & nOHNH $\begin{array}{c}\text { Drug- } \\
\text { likeness }\end{array}$ \\
\hline II & - & -1.13 & 382.2 & 121.80 & 9 & 0 & -14.79 \\
III & - & -0.27 & 293.0 & 98.51 & 6 & 1 & -2.68 \\
IV & - & -1.96 & 354.1 & 132.80 & 9 & 1 & -6.65 \\
Va & - & -2.35 & 332.2 & 101.34 & 6 & 0 & -7.02 \\
VIa & - & -4.04 & 392.2 & 135.63 & 9 & 0 & -5.53 \\
Vb & - & -2.26 & 316.1 & 101.34 & 6 & 0 & -7.21 \\
VIb & - & -4.05 & 376.1 & 135.60 & 9 & 0 & -5.54 \\
Vñ & - & -0.24 & 415.3 & 98.51 & 6 & 1 & -2.05 \\
VIc & - & -1.36 & 447.2 & 115.73 & 8 & 1 & -5.84 \\
Vd & - & -0.27 & 355.2 & 98.51 & 6 & 1 & -2.68 \\
VId & - & -1.37 & 433.3 & 116.63 & 8 & 1 & -5.90 \\
Vf & - & -0.48 & 399.2 & 98.51 & 6 & 1 & -3.80 \\
VIf & - & -1.36 & 425.3 & 115.8 & 8 & 1 & -5.88 \\
\hline
\end{tabular}

* Toxic risks: mutagenicity, oncogenicity, irritation, effect on reproductive function. $\log P$, lipophilicity coefficient; $\mathrm{nOH}$, number of $\mathrm{H}$ acceptors; nOHNH, number of $\mathrm{H}$ donors; TPSA, topological polar surface area. 
All compounds except for VIa exhibited antiplatelet activity from -4.5 to $-16.3 \%(p \leq 0.05)$ in the collagen-induced aggregation test. Pentoxifylline and acetylsalicylic acid did not exhibit biological activity in this test.

Ester $\mathbf{I I}$ and salts $\mathbf{V}$ and $\mathbf{V I}$ caused significant hypocoagulation, increasing the APTT by $4.7-9.3 \%(p \leq 0.05)$ as compared to the control and did not affect the PT and fibrinogen concentration. The effects of the tested compounds were significantly inferior to that of heparin sodium, which increased the APTT by $54.7 \%$.

The new compounds were analyzed for agreement with Lipinski's rule-of-5 $[17,18]$, toxic risks, and the drug-likeness parameter (similarity to a drug) using the Osiris DataWarrior program to discover compounds that could lead to potential drugs (drug candidates) after in vivo testing (Table 4).

A calculation of the toxic risks showed that mutagenic, oncogenic, and irritation properties and a negative effect on reproductive functioning were not predicted for the synthesized compounds.

The calculated physicochemical parameters of II-VI were found to satisfy Lipinski's rule-of- 5 . The molecular mass of the synthesized compounds was less than $447.2 \mathrm{~g} / \mathrm{mol}$. The lipophilicity coefficient fell in the range from -4.05 to -0.24 . The number of $\mathrm{H}$ acceptors was $<9 ; \mathrm{H}$ donors, 1. The topological polar surface area was $98.51-135.63 \AA^{2}$, which suggested that the synthesized compounds had good penetrating power through cell membranes. The drug-likeness parameter lay in the range from -14.79 to -2.05 , which confirmed the structures of the synthesized compounds were novel.

Thus, the antiplatelet activity in the ADP-induced aggregation test was greatest for III and VIb and comparable to that of acetylsalicylic acid. These compounds typically lacked toxic risks and were superior to the reference drugs in the collagen-induced aggregation test. The calculated drug-likeness parameter led to the conclusion that the search for new compounds with antiplatelet activity among this class of compounds was promising.

\section{REFERENCES}

1. E. Grove, Dan. Med. J., 59(9), B4506 (2012).

2. A. M. Wendelboe and G. E. Raskob, Circ. Res., 118(9), 1340 - 1347 (2016).

3. T. Iba, J. H. Levy, and M. Levi, Crit. Care Med., 48(9), 1358 - 1364 (2020).

4. S. Middeldorp, M. Coppens, and T. F. van Haaps, J. Thromb. Haemostasis, 18(8), 1995 - 2002 (2020).

5. J. D. McFadyen, M. Schaff, and K. Peter, Nat. Rev. Cardiol., 15(3), $181-191$ (2018).

6. B. H. Chong, J. Thromb. Haemostasis, 1(7), 1471-1478 (2003).

7. L. V. Popova and I. N. Bokarev, Prakt. Med., 6(82), 24-31 (2014).

8. A. V. Samorodov, F. Kh. Kamilov, A. R. Khalimov, et al., Biomeditsina, No. 3, 59-67 (2016).

9. E. E. Klen, F. A. Khaliullin, A. A. Spasov, et al., Khim.-farm. Zh., 42(9), 15 - 17 (2008); Pharm. Chem. J., 42(9), 610-612 (2008).

10. T. Sander, J. Freyss, M. von Korff, et al., J. Chem. Inf. Model., 55(2), 460 - 473 (2015).

11. D. A. Filimonov, A. A. Lagunin, T. A. Gloriozova, et al., Chem. Heterocycl. Compd., 50(3), 444 - 457 (2014).

12. Good Laboratory Practice Rules, Eurasian Economic Union on Circulation of Medicines, Approved by Decision No. 81 of the EAEC Committee of Nov. 3, 2016.

13. G. V. R. Born, Nature (London), 194(4832), 927 - 929 (1962).

14. A. N. Mironov (ed.), Handbook for Preclinical Drug Trials [in Russian], Vol. 1, Grif i K, Moscow (2013).

15. R. Kh. Khafiz'yanova, I. M. Burykin, and G. N. Aleeva, Mathematical Statistics in Experimental and Clinical Pharmacology [in Russian], Meditsina, Kazan' (2006).

16. A. G. Gil'manova, E. E. Klen, and F. A. Khaliullin, Bashk. Khim. Zh., 19(1), 53 - 56 (2012).

17. C. A. Lipinski, J. Pharmacol. Toxicol. Methods, 44(1), $235-249$ (2000).

18. C. A. Lipinski, F. Lombardo, B. W. Dominy, and P. J. Feeney, Adv. Drug Deliv. Rev., 46(1 - 3), 3 - 26 (2001). 